\title{
Clinical and epidemiological profile of patients infected by COVID-19 at a tertiary care centre in North India
}

\author{
Sadanand Prakash, ${ }^{1}$ Manas Mani Agrawal, ${ }^{1}$ Rajendra Kumar, ${ }^{1}$ Shubhangi Yadav ${ }^{2}$ \\ ${ }^{1}$ Department of Radiation Oncology, King George's Medical University, Lucknow; ${ }^{2}$ Department of Anatomy, All India \\ Institute of Medical Sciences, Raebareli, India
}

\begin{abstract}
A worldwide outbreak of a respiratory illness, first detected in December 2019 in Wuhan city, Hubei province, China is ongoing. The disease is caused by a novel coronavirus, SARS-CoV-2 and on February 11, 2020, was officially named Coronavirus Disease 2019 (COVID-19) by the World Health Organization. Within few weeks, it has spread globally to the extent that World Health Organization declared it as a global pandemic on March 11, 2020. India's first positive case was reported on January $30^{\text {th }}$ in Kerala. Before March $3^{\text {rd }}$, India had 3 cases of coronavirus in Kerala all of which were treated and discharged. On March $3^{\text {rd }}$, India's $4^{\text {th }}$ case was diagnosed in the state of Rajasthan. Indian government had announced a number of preventive measures to minimize the entry
\end{abstract}

Correspondence: Dr. Sadanand Prakash, Department of Radiation Oncology, King George's Medical University, Lucknow, 226003 India. Tel. +91.9450010158 .

E-mail: sadanand3030@gmail.com

Key words: COVID-19; SARS-CoV-2; coronavirus; RT-PCR; pneumonia.

Contributions: All the authors contributed equally to the study design, data collection, data analysis, data interpretation, literature search and writing of manuscript. They give their final approval of the version to be published.

Ethical approval: The article does not involve the participation of any human being and animal.

Patient consent: Not applicable.

Conflict of interest: The authors declare no conflict of interest.

Funding: None.

Received for publication: 2 May 2020.

Accepted for publication: 8 July 2020.

${ }^{\circ}$ Copyright: the Author(s), 2020

Licensee PAGEPress, Italy

Monaldi Archives for Chest Disease 2020; 90:1357

doi: 10.4081/monaldi.2020.1357

This article is distributed under the terms of the Creative Commons Attribution Noncommercial License (by-nc 4.0) which permits any noncommercial use, distribution, and reproduction in any medium, provided the original author(s) and source are credited. and spread of coronavirus. On March $3^{\text {rd }}$, India announced the suspension of all visas issued to Italy, Iran, South Korea and Japan. India banned international flights from March 22 ${ }^{\text {nd }}$. A 21-day lockdown across the country was imposed from March $26^{\text {th }}$, which later got further extended. Rigorous contact tracing and tracking of COVID patients and monitoring home quarantine helped in preventing community transmission.

The aim of this work is to describe the experience with clinical and epidemiologic features, as well as with the management of COVID-19 patients in north India. This is a descriptive study of the 17 COVID-19 infected patients confirmed with polymerase chain reaction (PCR) and admitted to a tertiary care centre in India from March $11^{\text {th }} 2020$ to April $16^{\text {th }} 2020$. The present work also provides insight in to treatment provided and final outcome of the patients infected with COVID-19 in India. Laboratory investigations in COVID-19 patients in the Indian subcontinent reveal lymphopenia as predominant finding in hemogram. Patients with older age and associated comorbidities (COPD, hypertension and diabetes) seem to have greater risk for lung injury, thereby requiring oxygen support during the course of disease.

\section{Introduction}

With each passing day, more cases of Coronavirus Disease (COVID-19) are being detected and unfortunately the fear of novel corona virus 2019 becoming a pandemic disease has come true. Constant efforts are being made in order to understand the genomics, hosts, modes of transmission and epidemiological link of nCoV-2019. As of now, whole genome sequence of the newly discovered coronavirus has already been decoded. COVID-19 is caused by a single-stranded RNA virus belonging to the genus Betacoronavirus named SARS-CoV-2 that affects the lower respiratory tract and manifests as pneumonia in humans [1-5]. This is the third coronavirus that has appeared among the human population in the last two decades. The other two were the Severe Acute Respiratory Syndrome coronavirus (SARS-CoV) outbreak in 2002 and the Middle East Respiratory Syndrome coronavirus (MERS-CoV) outbreak in 2012 [6].

Critical route of COVID-19 transmission is from human-tohuman via respiratory droplets, by direct contact with infected persons or contact with contaminated objects and surfaces. Typically, respiratory viruses are most contagious when a patient is symptomatic. However, previous studies provide evidence that human-to-human transmission may occur during the asymptomatic incubation period of COVID-19, which has been estimated to be between 1 and 14 days, average being 5-6 days [79].Including China, as of $19^{\text {th }}$ April 2020, this pandemic has 
involved around 200 countries, with a predominant disease load in USA, Spain, Italy, France, Germany, and UK. Up to $19^{\text {th }}$ April more than 2 million 3 hundred thousand confirmed COVID-19 infected cases with more than 160,000 deaths have been documented globally. In India more than 16,000 confirmed cases of COVID-19 with more than 500 deaths have been reported till date. It seems India will enter in community transmission stage soon.

Scientists have succeeded in recognizing the receptor i.e. ACE2 receptor for the attachment of SARS-CoV-2 [10]. Coronavirus human transmissibility and pathogenesis mainly depend on the interactions, including virus attachment, receptor recognition, protease cleaving and membrane fusion, of its transmembrane spike glycoprotein (S-protein) receptor binding domain, specific cell receptors (ACE2), and host cellular transmembrane serine protease (TMPRSS), with binding affinity of $2019-\mathrm{nCoV}$ about $73 \%$ of SARS-CoV.

The current study aims to describe epidemiological, clinical, laboratory and radiological characteristics, treatment, and outcomes of patients confirmed to have COVID-19 infection. We present data from a tertiary care centre in India used for isolation of suspected cases and management of COVID-19 positive patients.

\section{Methods}

King George's Medical University (KGMU) is a tertiary care hospital in Lucknow, capital city of Uttar Pradesh state of India and has been designated for isolation and management of suspected cases of COVID-19. Besides serving the 204,200 million people of Uttar Pradesh, KGMU also serves people of nearby states as Bihar and Uttarakhand. The current study is a retrospective observational case series of epidemiological features and clinical manifestations of COVID-19 positive patients who presented themselves to this centre during the outbreak of 2019-2020 from $11^{\text {th }}$ March 2020 to $11^{\text {th }}$ April 2020.

Since the first reports of the outbreak of SARS-CoV-2 came from China, the Indian Ministry of Health and Family Welfare (MoHFW) implemented protocol for testing of individuals (Figure 1).

Individuals with symptoms or requiring hospitalization for any medical treatment, who met the criteria for a suspected case, were admitted to our hospital. The isolation facility at our centre was assessed for preparedness according to a checklist standardized by MoHFW [11]. All the health-care workers caring for infected patients received comprehensive training and demonstrated competence in implementing infection control practices and procedures. The nasopharyngeal and oropharyngeal swabs were tested for detection of COVID-19 using quantitative polymerase chain reaction for confirmation. All laboratory confirmed cases were included in this study.

\section{Results}

Seventeen patients were included in the study over a period of time from $11^{\text {th }}$ March to $11^{\text {th }}$ April 2020. The mean age of the infected cases was 40.5 years, with a male preponderance (88.23\%). Two of the 17 confirmed cases were foreigners. Two of the total patients had recent travel history outside India, 1 patient was the relative of one of them. One patient was a health care worker in the same centre while three other patients were his rela- tives who came in contact with him. Demographic characteristics of the COVID-19 positive patients admitted in the centre is presented in Table 1.

The average lag between onset of symptoms of patients and hospital admission was 3 days. The average length of stay in hospital was 22.12 days. Approximately $35.29 \%$ patients were completely asymptomatic and of those who were symptomatic, the most common symptoms were fever and cough $(90.90 \%)$. Breathlessness was present only in 2 cases (18.18\%). Six patients (35.29\%) had underlying comorbid conditions in the form of hypertension, diabetes mellitus, coronary artery disease and chronic obstructive pulmonary disease (COPD). The mean duration from admission to getting $1^{\text {st }}$ COVID-19 sample negative was 16.8 days. The clinical and laboratory profile of the patients is summarized in Table 2 .

Chest X-ray was performed in all patients at initial presentation, and in 15 cases $(88.23 \%)$, it showed no abnormality. The remaining two patients showed bilateral consolidation of lower lobes of lungs. Both of them had underlying comorbid conditions as diabetes mellitus and hypertension, while one of them had COPD as well. Both of them required oxygen, while the patient with underlying DM and hypertension, a male aged 64 years, also required ventilatory support and later died.

Treatment given to asymptomatic patients was hydroxychloroquine with azithromycin. Treatment given to symptomatic patients without comorbidities was same as described for asymptomatic cases above plus oseltamivir. Symptomatic patients with comorbidities were prescribed same treatment as given to symptomatic cases without comorbidities with lopinavir. For fever, paracetamol was used.

Up to $16^{\text {th }}$ April 2020, sixteen patients recovered and advised home quarantine for 14 days as per guidelines while one patient had died. All discharged patients became asymptomatic and tested negative twice according to the guidelines.

\section{Standard operating procedure}

Patient in Emergency Room / Fever Clinic<smiles>[CH]=C</smiles>

Provide a surgical mask to every patient and maintain minimum 1-meter distance from each other<smiles>[C]=C</smiles>

Screening by doctor wearing PPE

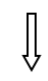

\begin{tabular}{|c|l|c|}
\hline N & \multicolumn{1}{|c|}{ History } & Score \\
\hline 1. & Travel history & 3 \\
\hline 2. & Contact with COVID-19 & 3 \\
\hline 3. & Fever and/or myalgia & 1 \\
\hline 4. & Dry cough & 1 \\
\hline 5. & Shortness of breath & 1 \\
\hline 6. & History of similar symptoms in family / friends & 1 \\
\hline 7. & Health care worker & 1 \\
\hline
\end{tabular}

\section{Score}

$\leq 3$-- Home quarantine for 14 days

4-8 -- Hospital quarantine and test

$>9$-- Shift to isolation ward

Figure 1. Indian Ministry of Health and Family Welfare protocol for testing of individuals. 
Table 1. Demographic profile of COVID-19 positive cases.

\begin{tabular}{lcc} 
& $\begin{array}{c}\text { Frequency } \\
\text { (total=17) }\end{array}$ & $\%$ \\
$\begin{array}{l}\text { Nationality } \\
\quad \text { Indian }\end{array}$ & 15 & 88.23 \\
Foreigner & 2 & 11.76 \\
Gender & & \\
$\quad$ Male & 15 & 88.23 \\
Female & 2 & 11.76 \\
\hline Age group & & \\
0-20 years & 4 & 23.52 \\
21-40 years & 6 & 35.29 \\
$\quad 41-60$ years & 3 & 17.64 \\
$\quad$ More than 60 years & 4 & 23.52 \\
History of travel outside India in the last 30 days & \\
$\quad$ Yes & 2 & 11.76 \\
$\quad$ No & 15 & 88.23 \\
\hline Exposure to positive case & & \\
Family exposure & 4 & 23.52 \\
Work place exposure & 2 & 11.76 \\
\hline
\end{tabular}

Table 2. Clinical and laboratory profile of COVID-19 positive cases.

\begin{tabular}{lcc} 
Profile & $\begin{array}{c}\text { Frequency } \\
\text { (total=17) }\end{array}$ & $\%$ \\
$\quad$ Asymptomatic & 7 & 41.17 \\
$\quad$ Symptomatic & 10 & 58.82 \\
Clinical symptoms & & \\
Cough & 10 & 58.82 \\
Fever & 10 & 58.82 \\
Breathlessness & 2 & 11.76 \\
\hline Comorbidities & & \\
Diabetes mellitus & 5 & 29.41 \\
Hypertension & 2 & 11.76 \\
Unstable angina & 1 & 5.88 \\
COPD & 1 & 5.88 \\
Hemogram & & \\
Normal & 6 & 35.29 \\
Leukocytosis, lymphopenia & 7 & 41.17 \\
Thrombocytopenia, lymphopenia & 4 & 23.52 \\
\hline
\end{tabular}

\section{Discussion}

Kerala's robust public health system, and a culture of thriving grassroots democracy with power devolving effectively to the village councils mainly helped in community outreach. Rigorous contact tracing and mass quarantine really mattered.

Complete lockdown was imposed across the country from March $26^{\text {th }}$.

The Ministry of Health and Family Welfare of India issued guidelines to contain spread of COVID-19. These include:

i) Use of face covers or masks to be mandatory.

ii) Individuals must maintain a minimum distance of 6 feet in public places.

iii) Practice frequent hand washing with soap. Use of alcoholbased hand sanitizers. iv) Use of PPE by employees giving essential services during lockdown.

v) Self- monitoring of health by all and reporting any illness at the earliest.

vi) Installation and use of Aarogya Setu App by all. It is an Indian open-source COVID-19 contact tracing, syndromic mapping and self-assessment digital service.

vii) Cleaning and regular disinfection of frequently touched surfaces.

The current study included 17 COVID-19 positive patients with the median age being 40.5 years, which is almost a decade younger than that reported by Huang et al. [12] (49.0 years) and a decade and a half younger than that reported by Wang et al. [13] (56.0 years) and Chen et al. [14] (55.5 years).

Patients who required oxygen support were above 60 years of age, thus demonstrating that elder patients were more likely to have lung injury and require ventilator support. Patients requiring oxygen support were more likely to have underlying comorbid conditions (100\%) including diabetes and hypertension.

Most of the patients having Covid-19 were male (88.23\%) which was higher than the figure reported by Huang et al and Chen et al who showed $73.0 \%$ male predominance.

Fever was the most common symptom present in our patients $(90.90 \%)$, which is similar to that reported by Huang et al. and Wang et al. where fever was the most common symptom found $(91.7 \%)$ and Guan et al. [6] (87.9\%).

Indian guidelines issued by the Indian Council of Medical Research allowed for the use of lopinavir and ritonavir for severe cases with respiratory failure or organ dysfunction [11]. However, a recent study has not found any benefit over time from the use of these drugs, both in terms of clinical improvement and mortality [15]. Hydroxychloroquine has also been evaluated in individual studies and may have a role in the management of COVID-19. Though initial results are not encouraging, we shall continue with the research for effective treatment and vaccination [16].

\section{Conclusions}

The current study showed variable range of COVID-19 presentation. Asymptomatic patients during the course of disease, despite being COVID-19 positive, pose a risk to the society as they can spread the infection and shall be strictly large epidemiological isolated. Old age and comorbid conditions are associated with poor prognosis. Close monitoring and large-scale control strategies will be needed to prevent widespread transmission within the community.

\section{References}

1. Chan JF, Kok KH, Zhu Z, et al. Genomic characterization of the 2019 novel human-pathogenic coronavirus isolated from a patient with atypical pneumonia after visiting Wuhan. Emerg Microbes Infect 2020;9:221-36.

2. Lu R, Zhao X, Li J, et al. Genomic characterisation and epidemiology of 2019 novel coronavirus: implications for virus origins and receptor binding. Lancet 2020;395:565-74..

3. Zhu N, Zhang D, Wang W, et al. A novel coronavirus from patients with pneumonia in China, 2019. N Engl J Med 2020;382:727-33.

4. Hung HM, Yang SL, Chen CJ, et al. Molecular epidemiology 
and clinical features of rhinovirus infections among hospitalized patients in a medical center in Taiwan. J Microbiol Immunol Infect 2019;52;233-41.

5. Lin GL, Lu CY, Chen JM, et al. Molecular epidemiology and clinical features of adenovirus infection in Taiwanese children, 2014. J Microbiol Immunol Infect 2019;52:215-24.

6. Guan W, Ni Z, Hu Y, et al. Clinical characteristics of coronavirus disease 2019 in China. N Engl J Med 2020;382:170820. doi: 10.1056/NEJMoa2002032.

7. Centers for Disease Control and Prevention. How COVID-19 spreads. Accessed on: 20 March 2020. Available from: https:// www.cdc.gov/coronavirus/2019-ncov/about/transmission. html

8. Rothe C, Schunk M, Sothmann P, et al. Transmission of 2019$\mathrm{nCoV}$ infection from an asymptomatic contact in Germany. $\mathrm{N}$ Engl J Med 2020;382:870-1.

9. Li Q, Guan X, Wu P, et al. Early transmission dynamics in wuhan, China, of novel coronavirus-infected pneumonia- N Engl J Med 2020;382:1199-207.

10. Wan Y, Shang J, Graham R, et al. Receptor recognition by novel coronavirus from Wuhan: An analysis based on decade- long structural studies of SARS. J Virol 2020;97:e00127-20. doi:10.1128/JVI.00127-20.

11. Indian Council of Medical Research. Media report on "Briefing on COVID19". Accessed on: 20 March 2020. Available from: https://main.icmr.nic.in/sites/default/files/MediaReport_COVID 19.pdf

12. Huang C. Wang Y, Li X et al. Clinical features of patients infected with 2019 novel coronavirus in 312 Wuhan, China. Lancet 2020;395:497-506.

13. Wang $\mathrm{D}, \mathrm{Hu} \mathrm{B}, \mathrm{Hu} \mathrm{C}$ et al. Clinical Characteristics of 138 Hospitalized patients with 2019 Novel Coronavirus infected Pneumonia in Wuhan, China. JAMA 2020;e201585.

14. Chen N, Zhou M, Dong X et al. Epidemiological and clinical characteristics of 99 cases of 2019 novel coronavirus pneumonia in Wuhan, China: a descriptive study. Lancet 2020:395:507-13.

15. Cao B, Wang Y, Wen D, et al. A trial of lopinavir-ritonavir in adults hospitalized with severe Covid-19. N Engl J Med 2020;382:1787-99.

16. Cortegiani A, Ingoglia $G$, Ippolito $M$, et al. A systematic review on the efficacy and safety of chloroquine for the treatment of COVID-19. J Crit Care 2020;57:279-83. 